\title{
Synthesis and catalytic antioxidant activity of functionalized chalcogen-containing GPx mimics
}

\author{
Damiano Tanini*, Beatrice Lupori, Pierandrea Lo Nostro, Antonella Capperucci \\ Dipartimento di Chimica "Ugo Schiff”, Via della Lastruccia 3-13, 50019 Sesto Fiorentino (FI), Italy \\ damiano.tanini@unifi.it
}

\begin{abstract}
The synthesis and the evaluation of the thiol peroxidase like antioxidant properties of $\beta$-functionalized symmetric and non-symmetric organochalcogenides have been explored. The tested catalysts were synthesized exploiting the reactivity of strained heterocycles with silyl chalcogenides. Oxygen-, nitrogen-, and sulfur-containing selenides and tellurides were efficiently achieved from the corresponding epoxides, aziridines, and thiiranes through mild and regioselective ring opening reactions. The thiol peroxidase catalytic activity was investigated by using the dithiothreitol (DTT) oxidation model. The results showed that the nature of the $\beta$-substituent plays a crucial role in modulating the catalytic properties of the studied GPx mimics. This effect can be reasonably ascribed to the presence of chalcogen bonding interactions involving the selenium or the tellurium atom and the heteroatom $(O, S)$ placed on the moiety at $C-2$.
\end{abstract}

\section{GRAPHICAL ABSTRACT}

Examples of Se or Te-containing
catalysts from strained heterocycles

KEYWORDS antioxidants; selenium; sulfur; tellurium; glutathione peroxidase; chalcogen bonding

\section{INTRODUCTION}

Organoselenides play an important role in the chemical sciences, with wide application in synthesis, material sciences, and medicinal chemistry. ${ }^{1}$ The main biological form of selenium is represented by L-selenocysteine (Sec). Due to the unique features of the selenium atom, Seccontaining selenoenzymes possess an array of important biological properties and their activity results dramatically increased with respect to the cysteine-containing analogues. 
Glutathione peroxidase (GPx), one of the most important mammalian selenoenzymes, is involved in the detoxification of aerobic living cells from reactive oxygen species (ROS), catalyzing the reduction of hydroperoxides at the expenses of two molecules of glutathione (GSH), which are, in turn, oxidized to GSSG. ${ }^{1,2}$

The lack of antioxidant defenses results in an increased ROS concentration, which has been related to the occurrence of a number of diseases, such as cancer, atherosclerosis, diabetes, neurodegenerative diseases, and immune disorder. ${ }^{3}$ In this scenario, the development of novel chalcogen-containing antioxidants has attracted growing interest among organic and medicinal chemists, as proven by the number of recent papers focusing on this topic. Several organoselenium $^{4}$ and, more recently, organotellurium $^{5}$ compounds have indeed been described as GPx mimics, being able to catalyze the reduction of hydroperoxides in the presence of thiols as cofactors. Intriguingly, organochalcogenides bearing $\mathrm{N}$ - and $\mathrm{O}-$, containing moieties have shown promising pharmacological properties. Furthermore, as the introduction of heteroatom-containing functional groups close to the chalcogen atom may result in a significant change of the catalytic antioxidant activity, the nature of these substituents has to be considered in order to design novel functionalized antioxidants with enhanced catalytic properties. ${ }^{6}$

We report herby our studies on the thiol peroxidase like antioxidant properties of variously functionalized symmetric and nonsymmetric selenides and tellurides, in order to evaluate the effect of different functional groups on the antioxidant activity.

\section{RESULTS AND DISCUSSION}

Our long standing interest in the chemistry of silyl chalcogenides led us to develop novel selective silicon-mediated procedures towards new variously functionalized selenides. ${ }^{7}$ Recently we also reported the synthesis of functionalized arylalkyl- and dialkyl-tellurides, exploiting the reactivity of strained heterocycles with (phenyltelluro)trimethylsilane ( $\left.\mathrm{PhTeSiMe}_{3}\right)$ or in situ generated $\mathrm{Li}_{2} \mathrm{Te}^{8}$ These findings are summarized in the Scheme 1. All the ring opening reactions herein described occurred with high regioselectivity and showed a broad scope and functional groups tolerability. 
A) Silicon-mediated synthesis of organoselenium compounds from three membered heterocycles

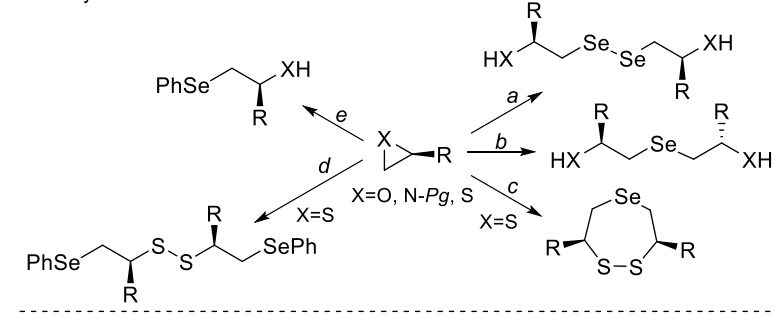

B) Synthesis of organotellurium compounds from three membered heterocycles

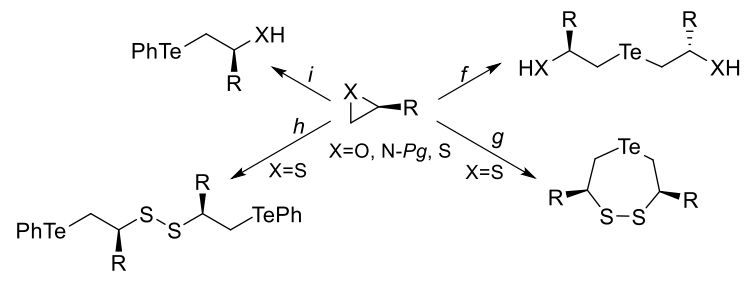

Scheme 1. Synthesis of functionalized chalcogencontaining molecules through the ring opening of three-membered heterocycles. Reagents and conditions: a) $\left(\mathrm{Me}_{3} \mathrm{Si}\right)_{2} \mathrm{Se}$ (1.6 eq.), TBAF, THF, r.t.; b) and c) $\left(\mathrm{Me}_{3} \mathrm{Si}\right)_{2} \mathrm{Se}$ (0.6 eq.), TBAF, THF, r.t.; d) $\mathrm{PhSeSiMe}_{3}$ (1.1 eq.), TBAF, r.t., 6 h; e) $\mathrm{PhSeSiMe}_{3}$ (1.1 eq.), TBAF, $0^{\circ} \mathrm{C} ; \mathrm{f}$ ) and $\left.\mathrm{g}\right) \mathrm{Li}_{2} \mathrm{Te}(0.5 \mathrm{eq}$, generated from elemental $\mathrm{Te}$ and $\left.\mathrm{LiBEt}_{3} \mathrm{H}\right)$, r.t., $12 \mathrm{~h}$; h) $\mathrm{PhTeSiMe}_{3}(1.1$ eq.), TBAF, r.t., $6 \mathrm{~h}$; i) $\mathrm{PhTeSiMe}_{3}$ (1.1 eq.), TBAF, $0^{\circ} \mathrm{C}$.

These procedures have also been applied to the synthesis of new sulfur-, selenium-, and tellurium-containing small molecules with interesting biological properties as antioxidants $^{9}$ and enzyme inhibitors. ${ }^{10}$

Having in hands a versatile approach to a plethora of differently substituted $\beta$ functionalized chalcogenides, we focused on evaluating their thiol peroxidase catalytic activity in order to elucidate whether the $\beta$ substituent could affect the catalytic properties.

The two homologous series of selenides and tellurides reported in Figure 1 were studied. The GPx-like activity of these compounds was assessed using the dithiothreitol (DTT) oxidation method reported by Iwaoka and co-workers. ${ }^{11}$ Results of this investigation are listed in Table 1. The time required to halve the initial $\mathrm{DTT}_{r e d}$ concentration, often indicated as $T_{50}$, is commonly used to compare the thiol peroxidase-like activity of similar compounds.

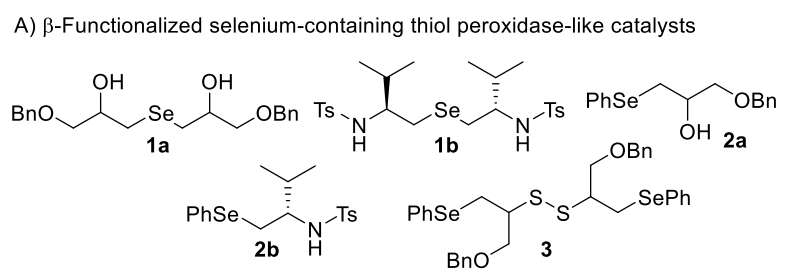

B) $\beta$-Functionalized tellurium-containing thiol peroxidase-like catalysts

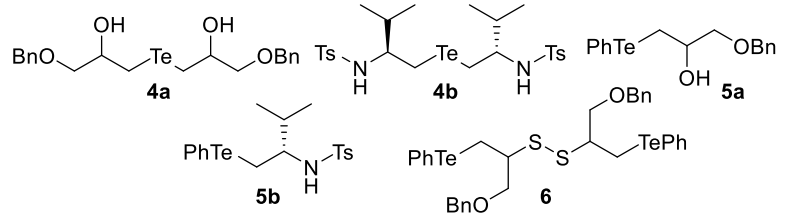

Figure 1. $\beta$-functionalized organochalcogenides as GPx-like catalysts.

As reported in Table 1, all the studied organotellurides proved to be much more 
active catalysts with respect to their selenium containing analogues. These findings are consistent with the results reported by other authors on the activity of organochalcogenides. ${ }^{12}$

Table 1. Thiol-peroxidase like activity of organoselenides and organotellurides according dithiothreitol (DTT) oxidation method.

\begin{tabular}{cccl} 
Cntry & Catalyst & Catalyst (mol\%) & \multicolumn{1}{c}{$c$} \\
\hline 1 & $\mathbf{1 a}$ & 10.0 & $3246( \pm 256)$ \\
2 & $\mathbf{1 b}$ & 10.0 & $7384( \pm 479)$ \\
3 & $\mathbf{2 a}$ & 10.0 & $328( \pm 34)$ \\
4 & $\mathbf{2 b}$ & 10.0 & $3186( \pm 198)$ \\
5 & $\mathbf{3}$ & 10.0 & $4870( \pm 387)$ \\
6 & $\mathbf{4 a}$ & 1.0 & $<60$ \\
7 & $\mathbf{4 b}$ & 1.0 & $214( \pm 34)$ \\
8 & $\mathbf{5 a}$ & 1.0 & $<60$ \\
9 & $\mathbf{5 b}$ & 1.0 & $600( \pm 61)$ \\
10 & $\mathbf{6}$ & 1.0 & $552( \pm 57)$ \\
\hline
\end{tabular}

${ }^{\mathrm{a}} T_{50}$ is the time required (in seconds) to reduce the initial thiol concentration with $50 \%$ after the addition of $\mathrm{H}_{2} \mathrm{O}_{2}$.

${ }^{\mathrm{b}} \mathrm{DTT}$ oxidation was monitored by the mean of ${ }^{1} \mathrm{H}$ NMR spectroscopy.

${ }^{\mathrm{C}}$ The mean $\pm \mathrm{SD}$ of three separate experiments are reported.

Furthermore, $\quad \beta$-hydroxy substituted derivatives 1a, 2a, 4a, and 5a showed better catalytic properties with respect to their $N$ Ts protected $\beta$-amino substituted analogues 1b, 2b, 4b, and 5b. Interestingly, also disulfides $\mathbf{3}$ and $\mathbf{6}$, bearing the phenylseleno and phenyltelluro moiety, respectively, behaved as poor catalysts, displaying a significantly lower activity when compared with $2 \mathbf{a}$ and $\mathbf{5 a}$. Therefore, the nature of the substituent at the C-2 plays an important role in determining the catalytic properties. We recently reported that this effect is reasonably due to the presence of chalcogen bonding interactions $(\mathrm{ChB})^{13}$ involving the oxygen or the sulfur and the catalytic chalcogen atom ( $\mathrm{Se}$ or $\mathrm{Te}$ ), as shown in Figure 2. ${ }^{9}$

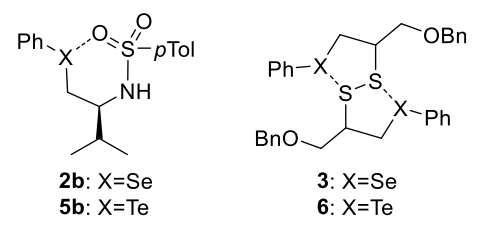

Figure 2. Reasonable intramolecular chalcogen bonding interactions for selenium- or telluriumcontaining amines $(\mathbf{2} \mathbf{b}, \mathbf{5 b})$ and disulfides $(\mathbf{3}, \mathbf{6})$.

Support for the proposed effect of ChB interactions on the GPx-like activity was provided by studying the catalytic properties of the $\beta$-phenyltelluro amine 7 and the $\beta$-phenyltelluro sulfide $\mathbf{8}$ which, due to the absence of the tosyl group and the disulfide moiety, cannot exhibit $\mathrm{Te} \cdot \cdots \mathrm{O} / \mathrm{S}$ nonbonded interactions. Organotellurides 7 and $\mathbf{8}$ were efficiently synthesized from the corresponding aziridine and thiirane 
(Scheme 2). The thiol peroxidase catalytic activity of $\mathbf{7}$ and $\mathbf{8}$, determined through the DTT oxidation test, was found to be excellent; having $T_{50}$ values shorter than 2 minutes, they proved to be approximately tenfold more active than the related derivatives $\mathbf{5 b}$ and $\mathbf{6}$ (Figure 3).

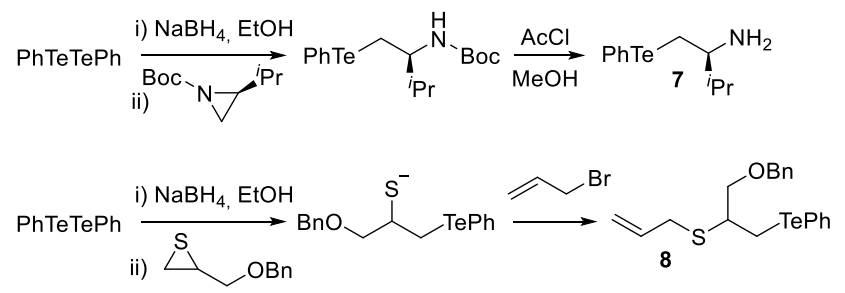

Scheme 2. Synthesis of amine $\mathbf{7}$ and allyl sulfide $\mathbf{8}$ bearing the $\beta$-phenyltelluro moiety.

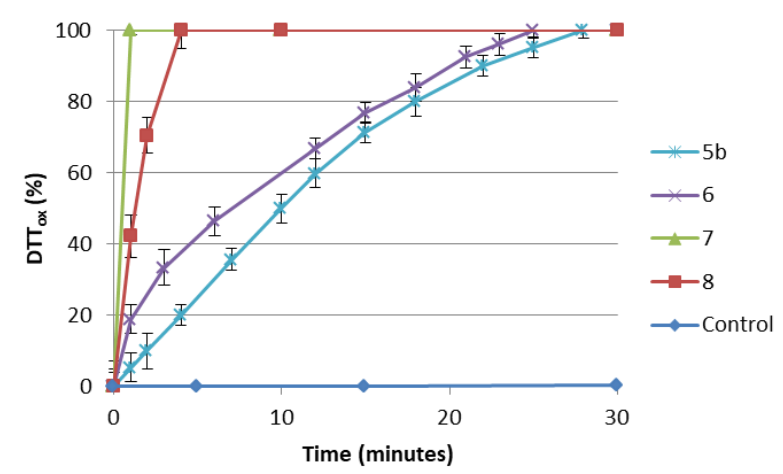

Figure 3. Dithiothreitol (DTT) oxidation GPx assay for compounds $\mathbf{5 b}, \mathbf{6}, \mathbf{7}$, and $\mathbf{8}$. Reaction conditions: $\left[\mathrm{DTT}_{\text {red }}\right]_{0}=0.14 \mathrm{M},\left[\mathrm{H}_{2} \mathrm{O}_{2}\right]_{0}=0.14 \mathrm{M},[\mathrm{Te}-$ containing catalyst $]=0.0014 \mathrm{M}, \mathrm{CD}_{3} \mathrm{OD}(0.6 \mathrm{~mL})$. The mean \pm SD of three separate experiments are reported.
These findings, highlighting the importance of the nature of the $\beta$-substituent in affecting the catalytic properties of GPx mimics, support the hypothesized central role of intramolecular chalcogen bonding interactions originated from the $\sigma$ hole in the $\sigma^{*}$ orbital of the covalent bonds of the Se or Te atom. Indeed, these interactions could hamper or slow the reactions of tellurium (or selenium) oxidation, thiol addition or reductive elimination occurring at the chalcogen catalytic center. ${ }^{13,14}$

\section{CONCLUSIONS}

In summary, we have achieved the synthesis of differently $\beta$-functionalized dialkyl- and aryl-alkyl-selenides and tellurides with remarkable thiol peroxidase like activity. Organotellurides exhibited higher catalytic activity with respect to the selenium containing analogues. The nature of the groups close to the catalytic chalcogen atom has been determined to play a crucial role in modulating the catalytic properties. Further studies on the synthesis and evaluation of novel catalytic antioxidants are currently under investigation in our laboratories. 


\section{REFERENCES}

1. Wirth, T.; Organoselenium Chemistry. Synthesis and Reactions; Wiley-VCH Verlag \& $\mathrm{Co}$, Weinheim, Germany, 2012; 361-379 and references cited therein.

2. (a) Nogueira, C. W.; Rocha, J. B. T. Toxicology and pharmacology of selenium: emphasis on synthetic organoselenium compounds. Arch. Toxicol. 2011, 85, 1313-1359. DOI: 10.1007/s00204-011-0720-3. (b) Bhabak, K. P.; Mugesh, G. Functional Mimics of Glutathione Peroxidase: Bioinspired Synthetic Antioxidants. Acc. Chem. Res. 2010, 43, 1408-1419. DOI: 10.1021/ar100059g.

3. (a) Seet, R. C. S.; Lee, C.-Y. J.; Lima, E. C. H.; Tan, J. J. H.; Quek, A. M. L.; Chong, W.-L.; Looi, W.-F.; Huang, S.-H.; Wang, H.; Chand, Y.-H.; Halliwell, B. Oxidative damage in Parkinson disease: Measurement using accurate biomarkers. Free Radical Biol. Med. 2010, 48, 560-566.

DOI: 0.1016/j.freeradbiomed.2009.11.026. (b) DalleDonne, I.; Rossi, R.; Colombo, R.; Giustarini, D.; Milzani, A. Biomarkers of oxidative damage in human disease. Clin. Chem. 2006, 52, 601623. DOI: 10.1373/clinchem.2005.061408. (c) Andersen, J. K. Oxidative stress in neurodegeneration: cause or consequence? Nat. Rev. Neurosci. 2004, 5, S18-S25. DOI: 10.1038/nrn1434. (d) Sies, H. Oxidative stress: From basic research to clinical application. Am. J. Med. 1991, 91, S31-S38. DOI: 10.1016/00029343(91)90281-2.

4. Inter Alia: (a) B. J. Bhuyan and G. Mugesh in Organoselenium Chemistry. Synthesis and Reactions, ed. T. Wirth, Wiley-VCH Verlag \& Co, Weinheim, Germany, 2012, 8, 361-379 and references cited therein. (b) Yoshida, S.; Kumakura, F.; Komatsu, I.; Arai, K.; Onuma, Y.; Hojo, H.; Singh, B. G.; Priyadarsini, K. I.; Iwaoka, M. Antioxidative glutathione peroxidase activity of selenoglutathione. Angew. Chem. Int. Ed. 2011, 50, 2125-2128. DOI: 10.1002/anie.201006939. (c) Alberto, E. E.; Soares, L. C.; Sudati, J. H.; Borges, A. C. A.; Rocha, J. B. T.; Braga, A. L. Efficient Synthesis of Modular Amino Acid Derivatives Containing Selenium with Pronounced GPx-Like Activity. Eur. J. Org. Chem. 2009, 4211-4214. DOI: 10.1002/ejoc.200900485. (d) Back, T.-G. Design and synthesis of some biologically interesting natural and unnatural products based on organosulfur and selenium chemistry. Can. J. Chem. 2009, 87, 1657-1674. DOI: 10.1139/V09133. (e) Muller, A.; Cadenas, E.; Graf, P.; Sies, H. A novel biologically active seleno-organic compound--I. Glutathione peroxidase-like activity in vitro and antioxidant capacity of PZ 51 (Ebselen). Biochem. Pharmacol. 1984, 33, 3235-3239. DOI: 10.1016/0006-2952(84)900832. For a review see: Pacula, A. J.; Mangiavacchi, F.; Sancineto, L.; Lenardao, E. J.; Scianowski, J.; Santi, C. An Update on "Selenium Containing Compounds from Poison to Drug Candidates: A Review on the GPx-like Activity". Curr. Chem. Biol. 2015, 9, 97-112. DOI : $10.2174 / 2212796810666160120220725$ and references cited therein.

5. (a) Bortoli, M.; Torsello, M.; Bickelhaupt, F. M.; Orian, L. Role of the Chalcogen (S, Se, Te) in the Oxidation Mechanism of the Glutathione Peroxidase Active Site. ChemPhysChem. 2017, 18, 2990-2998. DOI: 10.1002/cphc.201700743. (b) Fonseca, S. F.; Lima, D. B.; Alves, D.; Jacob, 
R. G.; Perin, G.; Lenardão, E. J.; Savegnago, L. Synthesis, characterization and antioxidant activity of organoselenium and organotellurium compound derivatives of chrysin. New J. Chem. 2015, 39, 3043-3050. DOI: 10.1039/C4NJ02329C. (c) Singh, V. P.; Poon, J. F.; Engman, L. Catalytic antioxidants: regenerable tellurium analogues of vitamin $\mathrm{E}$. Org. Lett. 2013, 15, 6274-6277. DOI: 10.1021/ol403131t. (d) Jamier, V.; Ba, L. A.; Jacob, C. Selenium- and tellurium-containing multifunctional redox agents as biochemical redox modulators with selective cytotoxicity. Chem. Eur. J. 2010, 16, 10920-10928. DOI: 10.1002/chem.201000884. (e) Braga, A. L.; Alberto, E. E.; Soares, L. C.; Rocha, J. B. T.; Sudati, J. H.; Roos, D. H. Synthesis of telluroamino acid derivatives with remarkable GPx like activity. Org. Biol. Chem. 2009, 7, 4345. DOI: 10.1039/B814990A. (f) Malmström, J.; Jonsson, M.; Cotgreave, I. A.; Hammarström, L.; Sjödin, M.; Engman, L. The Antioxidant Profile of 2,3-Dihydrobenzo[ $b]$ furan-5-ol and Its 1-Thio, 1-Seleno, and 1-Telluro Analogues. J. Am. Chem. Soc., 2001, 123, 3434-3440. DOI: 10.1021/ja0035811.

6. (a) Selvakumar, K.; Shah, P.; Singh, H. B.; Butcher, R. J. Synthesis, structure, and glutathione peroxidase-like activity of amino acid containing ebselen analogues and diaryl diselenides. Chem. Eur. J. 2011, 17, 1274112755. DOI: 10.1002/chem.201100930. (b) Bhabak, K. P.; Mugesh, G. A Simple and Efficient Strategy To Enhance the Antioxidant Activities of Amino-Substituted Glutathione
Peroxidase Mimics. Chem. Eur. J. 2008, 14, 8640-8651. DOI: 10.1002/chem.200800963.

7. (a) Tanini, D.; Tiberi, C.; Gellini, C.; Salvi, P. R.; Capperucci, A. A Straightforward Access to Stable $\beta$-Functionalized Alkyl Selenols. $A d v$. Synth. Catal. 2018, 360, 3367-3375. DOI: 10.1002/adsc.201800602. (b) Tanini, D.; Caperucci, A.; Degl'Innocenti, A. Bis(trimethylsilyl)selenide in the Selective Synthesis of $\beta$-Hydroxy, $\beta$-Mercapto, and $\beta$ Amino Diorganyl Diselenides and Selenides Through Ring Opening of Strained Heterocycles. Eur. J. Org. Chem. 2015, 357-369. DOI: 10.1002/ejoc.201403015. (c) Capperucci, A.; Tanini, D.; Borgogni, C.; Degl'Innocenti, A. Thiosilane- and Organoselenosilane-Mediated Novel Access to 3,7-Disubstituted-1,2,5trithiepanes and -1,2,5-dithiaselenepanes. Heteroatom Chem. 2014, 25, 678-683. DOI: 10.1002/hc. (d) Capperucci, A.; Tanini, D. Silicon-assisted synthesis and functionalization of sulfurated and selenated compounds. Phosphorus, Sulfur Silicon Relat. Elem. 2015, 190, 1320-1338. DOI: 10.1080/10426507.2015.1024790

8. Tanini, D.; Grechi, A.; Dei, S.; Teodori, E.; Capperucci, A. An easy one-step procedure for the synthesis of novel $\beta$-functionalised tellurides. Tetrahedron 2017, 73, 5646-5653. DOI 10.1016/j.tet.2017.07.061.

9. (a) Tanini, D.; Grechi, A.; Dei, S.; Teodori, E.; Capperucci, A. Novel functionalized organotellurides with enhanced thiol peroxidase catalytic activity. New J. Chem. 2018, 42, 60776083. DOI: 10.1039/C8NJ00700D. (b) Tanini, 
D.; D'Esopo, V.; Chen, D.; Barchielli, G.; Capperucci, A. Novel sulfur and seleniumcontaining antioxidants: Synthesis and evaluation of their GPx-like activity. Phosphorus, Sulfur Silicon Relat. Elem. 2017, 192, 166-168. DOI:

10.1080/10426507.2016.1252365.

Menichetti, S.; Capperucci, A.; Tanini, D.; Braga, A.-L.; Botteselle, G. V.; Viglianisi, C. A One-Pot Access to Benzo[b][1,4]selenazines from 2-Aminoaryl Diselenides. Eur. J. Org. Chem., 2016, 3097-3102. DOI: 10.1002/ejoc.201600351.

10. (a) Angeli, A.; Tanini, D.; Capperucci, A.; Malevolti, G.; Turco, F.; Ferraroni, M.; Supuran, C. T. Synthesis of different thio-scaffolds bearing sulfonamide with subnanomolar carbonic anhydrase II and IX inhibitory properties and X-ray investigations for their inhibitory mechanism. Bioorg. Chem. 2018, 81, 642-648. DOI: 10.1016/j.bioorg.2018.09.028. (b) Angeli, A.; Tanini, D.; Capperucci, A.; Supuran, C. T. Synthesis of Novel Selenides Bearing Benzenesulfonamide Moieties as Carbonic Anhydrase I, II, IV, VII, and IX Inhibitors. ACS Med. Chem. Lett. 2017, 8, 1213-1217. DOI: 10.1021/acsmedchemlett.7b00387. (c) Angeli,
A.; Tanini, D.; Capperucci, A.; Supuran, C. T. First evaluation of organotellurium derivatives as carbonic anhydrase I, II, IV, VII and IX inhibitors. Bioorg. Chem. 2018, 76, 268-272. DOI: 10.1016/j.bioorg.2017.12.010.

11. Kumakura, F.; Mishra, B.; Priyadarsini, K.-I.; Iwaoka, M. A Water-Soluble Cyclic Selenide with Enhanced Glutathione Peroxidase-Like Catalytic Activities. Eur. J. Org. Chem. 2010, 440-445. DOI: 10.1002/ejoc.200901114.

12. Nogueira, C. W.; Zeni, G.; Rocha, J. B. T. Organoselenium and organotellurium compounds: toxicology and pharmacology. Chem. Rev. 2004, 104, 6255-6285. DOI: 10.1021/cr0406559.

13. Pascoe, D. J.; Ling, K. B.; Cockroft, S. L. The Origin of Chalcogen-Bonding Interactions. $J$. Am. Chem. Soc. 2017, 139, 15160-15167. DOI: 10.1021/jacs.7b08511.

14. Nascimento, V.; Alberto, E. E.; Tondo, D. W.; Dambrowski, D.; Detty, M. R.; Nome, F.; Braga, A. L. GPx-Like activity of selenides and selenoxides: experimental evidence for the involvement of hydroxy perhydroxy selenane as the active species. J. Am. Chem. Soc. 2012, 134, 138-141. DOI: 10.1021/ja209570y. 